\title{
Spatial Analysis of the Tuberculosis Cure in Primary Care in Rio de Janeiro, Brazil
}

\author{
José Carlos Prado Junior \\ Oswaldo Cruz Foundation: Fundacao Oswaldo Cruz \\ Roberto de Andrade Medronho ( $\nabla$ robertoamedronho@gmail.com ) \\ Universidade Federal do Rio de Janeiro https://orcid.org/0000-0003-4073-3930
}

\section{Research article}

Keywords: Family Health, Infectious Diseases, Primary Care, Public Health, Respiratory Diseases, Tropical Medicine

Posted Date: December 8th, 2020

DOI: https://doi.org/10.21203/rs.3.rs-122530/v1

License: (a) (i) This work is licensed under a Creative Commons Attribution 4.0 International License. Read Full License 


\section{Abstract}

Background: Tuberculosis (TB) presents a high burden of disease and is considered a global emergency by the World Health Organization (WHO), consisting of the most important cause of death from infectious disease in adults. It is related directly to access to health services and socioeconomic factors. Primary health care provides greater linking people to health services and greater medication adherence in some chronic diseases. Also, it provides supervised treatment and the search for more effective contacts.

Objective: This paper aims to compare the tuberculosis cure among the areas covered and not covered by the family health teams from 2012 to 2014.

Methods: A cross-sectional study was carried out in Rio de Janeiro. The variables were obtained from the Notifiable Diseases Information System for Tuberculosis (SINAN-TB) and the socioeconomic variables from the 2010 national census. The socioeconomic variables were selected from the multivariate analysis using principal factors analysis techniques. For the spatial analysis was used a generalized additive model (GAM).

Results: Association was found between TB cure and education, alcoholism, contacts search, serology for HIV and the elderly. People with family health coverage between 35 and 41 months had 1,64 more chance of cure when compared to people without coverage $(95 \% \mathrm{Cl} 1.07$ to 2.51$)$.

Conclusion: From the spatial analysis, it was possible to identify areas with less chance of cure for tuberculosis in the municipality.

\section{Highlights}

- Illiterate people were less likely to the tuberculosis cure.

- The tuberculosis cure was less likely in people with HIV and alcohol abuse.

- The cure for tuberculosis was greater in areas with high family health coverage.

\section{Background}

Tuberculosis (TB) is an infectious disease of great magnitude and importance in the world. It was declared a worldwide emergency disease by the World Health Organization (WHO) in 1993 and is the largest cause of death by infectious diseases in adults ${ }^{1}$.

Brazil is one of WHO 22 priority TB control countries and ranked 16th in 2014. These countries together account for $80 \%$ of global cases.

In 2014, the incidence rate in the municipality of Rio de Janeiro was $66.8 / 100,000$ inhabitants. The cure rate of smear-positive pulmonary tuberculosis in the city was $69.2 \%$, below that recommended by the WHO, which is $85 \%^{2}$.

The disease has a direct relationship with the misery and social exclusion; therefore, the most socially vulnerable people have a greater probability of developing and proliferating this disease. Socioeconomic 
factors hamper people's access to health services ${ }^{3}$ which in turn contribute to delayed TB diagnosis and treatment, increasing the possibility of abandoning treatment, one of the main obstacles to control this disease ${ }^{3}$.

Primary health care (PHC) plays a key role in curing tuberculosis because the access of health system ${ }^{4}$ and more adherence to TB treatment, reaching the most vulnerable populations ${ }^{4}$. An association between PHC and reduced treatment abandonment rate and lower mortality due to tuberculosis is described ${ }^{5}$.

The municipality of Rio de Janeiro (MRJ) had 3,5\% of PHC coverage in 2008. In the next years, MRJ had a huge growth of PHC coverage reaching $46.16 \%$ in $2015^{5,7}$.

Currently, there are two PHC care models: (1) Family Health Teams, with a more comprehensive supply of health services based on PHC principles (access, longitudinally, care coordination and comprehensiveness) ${ }^{4}$ with general practitioners and nurses with territorially-defined health responsibility; and (2) Traditional PHC, with medical care based on gender and age (pediatrics, gynecology, medical clinic) ${ }^{5}$.

Considering that TB is a disease strongly related to socioeconomic factors $8,9,10,11,12,13$, as well as to access to health services ${ }^{3,5}$, it is necessary to evaluate the relationship of PHC coverage and cure of TB in the municipality.

This paper aims to evaluate the spatial distribution of new cases of tuberculosis with cure outcome in residents of MRJ in the period 2012-2014, by PHC coverage, controlling socioeconomic, demographic, and epidemiological factors.

\section{Methods}

This cross-sectional study was carried out in MRJ, correlating TB cure with family health coverage and socioeconomic, demographic, and epidemiological variables. The municipality is located in the southeast of the country, with exclusively urban population estimated at $6,476,631$ inhabitants in $2015^{14}$.

The study population is comprised of new cases of tuberculosis residing in the MRJ notified in the period 2012-2014. All cases were eligible to be part of the study to minimize selection bias.

The geo-referencing technique was used from the residence address to identify family's health coverage, assigning a geographical position for each record (latitude and longitude). The PHC coverage maps were developed by the Municipal Health Secretariat of Rio de Janeiro and correspond to the existing coverage in 2012, 2013 and 2014, with reference to the month of December. Georeferencing of addresses was done using the "Geocode" tool made available by Google Maps through a free Application Programming Interface (API).

This process utilized the Google's streets and location base. The accuracy of georeferencing can be evaluated from a score ranging from 0 to 10, (0-not found, 1-country level, 2-state, 3-subregion, 4-city, 5-Zip Code, 6streets, 7-intersection between streets, 8-address, 9-name of the building or trade, 10-maximum precision). Addresses with a score lower than " 5 " were considered as losses. Records with scores between " 8 " and " 10 " 
were considered with acceptable accuracy. The remaining records were manually reviewed. Of the 14,384 georeferenced records, the precise geographic coordinates of 3,484 records $(24.22 \%)$ could not be determined, characterizing losses of the georeferenced sample. The total number of georeferenced records was 10,900 new closed cases.

The outcome variable considered in this study was the "TB cure outcome" (yes/no) obtained from the Notifiable Diseases Information System for Tuberculosis (SINAN-TB) and the exposure variable was "PHC coverage", expressed by the "time (in months) between the implantation of the heath teams and TB diagnosis".

The selection of variables was based on the theoretical TB cure model based on the dimensions "environment", "individual factors", "access to healthcare service" and "social status". The model includes demographic, social, epidemiological, access and use of health services variables.

The variables selected from the SINAN-TB were: age; gender; race/color (white/non-white); schooling; “HIV coinfection" (yes/no); "alcohol abuse history" (yes/no); "Contact search" (yes/no); "serology for HIV" (positive, negative, not performed); "supervised treatment" (yes/no).

Considering that there is a large number of socioeconomic variables from the 2010 demographic census $\left(\right.$ IBGE, 2011) ${ }^{15}$, a multivariate analysis was performed using the main components analysis technique. Thus, the TB cure-related realms ("agglomeration", "household conditions", "demographic", "schooling", "income") were established from the theoretical model related to the "social condition" and for each realm, the variables that, to a lesser extent, represent the other variables of that realm were selected.

The socioeconomic and demographic variables resulting from this analysis were: "average monthly income of the person in charge (R\$)"; "average number of residents per household"; "population density in the census sector"; "Density of dwellers/rooms"; "proportion of permanent private households with bathrooms for the exclusive use of residents or water closet and sanitary sewage via general sewer or rainwater network"; "Proportion of permanent households with electricity"; "average number of toilets per permanent private residence"; "aging rate".

The variables obtained from the Demographic Census represent the averages and proportions of each census tract. These values were repeated for each individual resident in the same census tract since these variables in this level of aggregation show high homogeneity. The other variables were analyzed from the individual level.

R software (R Development Core Team, 2016) ${ }^{16}$ was used for data descriptive analysis through bivariate logistic regression (gross analysis), exploratory analysis, multivariate analysis, kernel estimation and spatial analysis was performed using the R software.

During TB spatial exploratory analysis, we observed the distribution of points and identification of possible clusters through the point density estimation technique, defined as Kernel density estimation, which consists of generating a point density surface within a region of influence, weighted by the distance of each from the location of interest, for the visual identification of "hot areas" on the map. Bandwidths from $500 \mathrm{~m}$ to 3,000 m 
were tested, with $250 \mathrm{~m}$ increments. A matrix of $500 \times 500$ points and a radius of 2,500 m was used because it was considered the most appropriate for highlighting strategic areas. We generated maps with estimates of TB incidence rate through the kernel ratio between reported cases of TB and the kernel of the population.

Spatial analysis was based on the generalized additive model (GAM), which can be considered an extension of generalized linear models, with the inclusion of a non-parametric element by smoothing functions. The model has the great advantage of being more flexible and relatively simple to interpret ${ }^{17}$. The Thin Plate Regression Splines smoothing technique was used.

The construction of the generalized additive models was performed through manual selection, based on the essential factors of the theoretical framework, not only considering the statistically significant variables in the bivariate analysis, but also those of epidemiological importance.

We did not only consider the p-value of each association, but the importance previously described of each variable and the impact on the explanatory power of the model. Only those variables with a clear negative impact under the explanatory power of the model, observed through deviance, were removed.

The software for constructing family health coverage maps and spatial data queries was ArcGIS, version 10.2.2 ${ }^{18}$ in Latlong/WGS84 projection, available in the shapefile extension.

During the analyses, the following additional packages of $\mathrm{R}$ were used: $\mathrm{car}^{19}, \mathrm{mgcv}^{20}, \mathrm{descr}^{21}, \mathrm{sp}^{22}, \mathrm{sdep}^{23}$, maptools ${ }^{24}$, splancs ${ }^{25}$, fields ${ }^{26}$, RColorBrewer $^{27}$, ggplot2 ${ }^{28}$.

\section{Results}

During the years 2012 to 2014, 16,363 new TB cases of MRJ residents were identified. Of these, 905 cases were excluded from the study due to lack of closure in addition to 161 cases of street population and other 913 records of institutionalized persons, since these individuals cannot be classified in terms of family health coverage, leaving out 14,384 records for the study.

The closing percentage for this period was $94.47 \%$. The cure rate was $71.57 \%(11,063$ new cases) of the total cases closed. The mean incidence rate was 84.91 cases/100,000 inhabitants. In the same period, there were 725 cases of death by TB resulting in a mean specific mortality rate of 3.76 cases per 100,000 inhabitants, and the case fatality rate was $4.69 \%$ among new cases closed. Median age was 38 years.

The estimation of the incidence rate from the Kernel ratio shows that the "hot areas" were mainly concentrated in the southern zone (Rocinha), followed by the northern zone (Complexo do Alemão, Acari, Pavuna) and the western zone (Senador Camará, Realengo).

Most cases occurred in males $(\mathrm{n}=8,919 ; 62.0 \%)$, of non-white race $/$ color $=7,839,54.5 \%)$ and illiterates $(\mathrm{n}=$ $4,493,31.2 \%)$.

An association with several variables was found (Table 1) from the crude bivariate analysis of TB cure with socioeconomic, demographic variables and epidemiological variables. In relation to age, there is a lower 
probability of cure in the age range $>25$ to 50 years (OR $0.86,95 \% \mathrm{Cl} 0.78-0.94$ ) compared to the reference category ( 0 to 25 years). Among individuals aged $>80$ years, the probability of cure decreases even further (OR $0.44,95 \% \mathrm{Cl} 0.32-0.59)$. Women were 1.51 times (95\% $\mathrm{Cl} 1.39-1.63)$ more likely to be cured than men. Non-white people were less likely to be cured $(\mathrm{OR} 0.68,95 \% \mathrm{Cl} 0.62-0.73)$ than white people. The higher the level of schooling, the greater the probability of cure compared to illiterate people. 
Table 1

Analysis of the tuberculosis cure according to socioeconomic variables.

\begin{tabular}{|c|c|c|c|c|c|c|c|c|c|}
\hline \multirow{3}{*}{$\begin{array}{l}\text { Variables } \\
(N=14,384)\end{array}$} & \multicolumn{9}{|l|}{ Cure } \\
\hline & \multicolumn{2}{|l|}{ Yes } & \multicolumn{2}{|l|}{ No } & \multicolumn{2}{|l|}{ Total } & \multirow[t]{2}{*}{ OR } & \multirow[t]{2}{*}{ Cl 95\% } & \multirow{2}{*}{$\begin{array}{l}p- \\
\text { value }\end{array}$} \\
\hline & $\mathrm{n}$ & $\%$ & $\mathbf{N}$ & $\%$ & $\mathbf{N}$ & $\%$ & & & \\
\hline \multicolumn{10}{|l|}{ Age } \\
\hline $\begin{array}{l}0 \text { to } \\
25 \text { years }\end{array}$ & 2,759 & $26.2 \%$ & 926 & $24.0 \%$ & 3,685 & $25.6 \%$ & 1.00 & & \\
\hline $\begin{array}{l}>25 \text { to } \\
50 \text { years }\end{array}$ & 4,865 & $46.2 \%$ & 1,908 & $49.5 \%$ & 6,773 & $47.1 \%$ & 0.86 & $\begin{array}{l}0.78- \\
0.94\end{array}$ & $\begin{array}{l}<.001^{b} \\
\end{array}$ \\
\hline $\begin{array}{l}>50 \text { to } \\
80 \text { years }\end{array}$ & 2,745 & $26.1 \%$ & 923 & $23.9 \%$ & 3,668 & $25.5 \%$ & 1.00 & $\begin{array}{l}0.9- \\
1.11\end{array}$ & 0.975 \\
\hline$>80$ years & 96 & $0.9 \%$ & 74 & $1.9 \%$ & 170 & $1.2 \%$ & 0.44 & $\begin{array}{l}0.32- \\
0.59\end{array}$ & $\begin{array}{l}< \\
0.001^{b}\end{array}$ \\
\hline Ignored & 65 & $0.6 \%$ & 23 & $0.6 \%$ & 88 & $0.6 \%$ & 0.95 & $\begin{array}{l}0.59- \\
1.53\end{array}$ & 0.839 \\
\hline \multicolumn{10}{|l|}{ Sex } \\
\hline Male & 6,264 & $59.5 \%$ & 2,655 & $68.9 \%$ & 8,919 & $62.0 \%$ & 1.00 & & \\
\hline Female & 4,264 & $40.5 \%$ & 1,199 & $31.1 \%$ & 5,463 & $38.0 \%$ & 1.51 & $\begin{array}{l}1.39- \\
1.63\end{array}$ & $\begin{array}{l}<.001^{b} \\
0\end{array}$ \\
\hline \multicolumn{10}{|l|}{ Race/color } \\
\hline White & 4,243 & $40.3 \%$ & 1,169 & $30.3 \%$ & 5,412 & $37.6 \%$ & $1.00^{\mathrm{a}}$ & & \\
\hline Non-white & 5,57 & $52.9 \%$ & 2,269 & $58.9 \%$ & 7,839 & $54.5 \%$ & 0.68 & $\begin{array}{l}0.62- \\
0.73\end{array}$ & $\begin{array}{l}< \\
0.001^{b}\end{array}$ \\
\hline Ignored & 717 & $6.8 \%$ & 416 & $10.8 \%$ & 1,133 & $7.9 \%$ & 0.47 & $\begin{array}{l}0.41- \\
0.54\end{array}$ & $\begin{array}{l}< \\
0.001^{b}\end{array}$ \\
\hline \multicolumn{10}{|l|}{ Schooling } \\
\hline Illiterate & 3,186 & $30.3 \%$ & 1,307 & $33.9 \%$ & 4,493 & $31.2 \%$ & $1.00^{\mathrm{a}}$ & & \\
\hline $\begin{array}{l}\text { Primary } \\
\text { school }\end{array}$ & 1,747 & $16.6 \%$ & 496 & $12.9 \%$ & 2,243 & $15.6 \%$ & 1.44 & $\begin{array}{l}1.28- \\
1.63\end{array}$ & $\begin{array}{l}< \\
0.001^{b}\end{array}$ \\
\hline
\end{tabular}

SOURCE: Municipal databases of SINAN-TB and IBGE, 2010. Updated 10/01/2016.

Abbreviations: $n$, sampling size; OR, odds ratio; SD, standard deviation; $p$-value, significance level.

a reference category; ${ }^{b}$ statistical significance $p<0.05$ 


\begin{tabular}{|c|c|c|c|c|c|c|c|c|c|}
\hline \multirow{3}{*}{$\begin{array}{l}\text { Variables } \\
(N=14,384)\end{array}$} & \multicolumn{9}{|l|}{ Cure } \\
\hline & \multicolumn{2}{|l|}{ Yes } & \multicolumn{2}{|l|}{ No } & \multicolumn{2}{|l|}{ Total } & \multirow[t]{2}{*}{ OR } & \multirow[t]{2}{*}{$\mathrm{Cl} 95 \%$} & \multirow{2}{*}{$\begin{array}{l}p- \\
\text { value }\end{array}$} \\
\hline & $\mathrm{n}$ & $\%$ & $\mathbf{N}$ & $\%$ & $\mathbf{N}$ & $\%$ & & & \\
\hline $\begin{array}{l}\text { Secondary } \\
\text { school }\end{array}$ & 1,923 & $18.3 \%$ & 389 & $10.1 \%$ & 2,312 & $16.1 \%$ & 2.03 & $\begin{array}{l}1.79- \\
2.3\end{array}$ & $\begin{array}{l}<.001^{b} \\
-\end{array}$ \\
\hline $\begin{array}{l}\text { Higher } \\
\text { education }\end{array}$ & 619 & $5.9 \%$ & 100 & $2.6 \%$ & 719 & $5.0 \%$ & 2.54 & $\begin{array}{l}2.04- \\
3.17\end{array}$ & $<.001^{b}$ \\
\hline Ignored & 3,055 & $29.0 \%$ & 1,562 & $40.5 \%$ & 4,617 & $32.1 \%$ & 0.80 & $\begin{array}{l}0.73- \\
0.88\end{array}$ & $<001^{b}$ \\
\hline \multicolumn{7}{|c|}{$\begin{array}{l}\text { Monthly average income of the } \\
\text { responsible person (R\$) }\end{array}$} & 1.001 & $\begin{array}{l}1.001- \\
1.004\end{array}$ & $<0.001^{b}$ \\
\hline \multicolumn{7}{|c|}{$\begin{array}{l}\text { Average number of residents in permanent } \\
\text { private households }\end{array}$} & 0.77 & $\begin{array}{l}0.69- \\
0.85\end{array}$ & $<.001^{b}$ \\
\hline \multicolumn{7}{|c|}{$\begin{array}{l}\text { Percentage of permanent households } \\
\text { with electricity }\end{array}$} & 2.16 & $\begin{array}{l}0.57- \\
8.06\end{array}$ & $<.001^{b}$ \\
\hline \multicolumn{7}{|c|}{$\begin{array}{l}\text { Average number of restrooms per } \\
\text { household }\end{array}$} & 1.33 & $\begin{array}{l}1.20- \\
1.48\end{array}$ & $<.001^{b}$ \\
\hline Aging rate & & & & & & & 5.87 & $\begin{array}{l}2.77- \\
12.43\end{array}$ & $<.001^{b}$ \\
\hline \multicolumn{10}{|l|}{ AIDS Coinfections } \\
\hline Yes & 606 & $8.0 \%$ & 643 & $23.1 \%$ & 1,249 & $12.1 \%$ & 1.00 & & \\
\hline No & 6.977 & $92.0 \%$ & 2,139 & $76.9 \%$ & 9,116 & $87.9 \%$ & 3.46 & $\begin{array}{l}3.07- \\
3.91\end{array}$ & $<.001^{b}$ \\
\hline \multicolumn{10}{|l|}{ HIV test performed } \\
\hline Positive & 744 & $7.1 \%$ & 707 & $18.3 \%$ & 1,451 & $10.1 \%$ & 1.00 & & \\
\hline Negative & 7.573 & $71.9 \%$ & 1,96 & $50.9 \%$ & 9,533 & $66.3 \%$ & 3.67 & $\begin{array}{l}3.28- \\
4.12\end{array}$ & $<.001^{b}$ \\
\hline $\begin{array}{l}\text { Not } \\
\text { performed }\end{array}$ & 2.213 & $21.0 \%$ & 1,187 & $30.8 \%$ & 3,4 & $23.6 \%$ & 1.77 & $\begin{array}{l}1.56- \\
2.01\end{array}$ & $\begin{array}{l}<.001^{b} \\
0\end{array}$ \\
\hline
\end{tabular}

\section{SOURCE: Municipal databases of SINAN-TB and IBGE, 2010. Updated 10/01/2016.}

Abbreviations: $n$, sampling size; OR, odds ratio; SD, standard deviation; $p$-value, significance level.

a reference category; ${ }^{b}$ statistical significance $p<0.05$ 


\begin{tabular}{|c|c|c|c|c|c|c|c|c|c|}
\hline \multirow{3}{*}{$\begin{array}{l}\text { Variables } \\
(N=14,384)\end{array}$} & \multicolumn{9}{|l|}{ Cure } \\
\hline & \multicolumn{2}{|l|}{ Yes } & \multicolumn{2}{|l|}{ No } & \multicolumn{2}{|l|}{ Total } & \multirow[t]{2}{*}{ OR } & \multirow[t]{2}{*}{$\mathrm{Cl} 95 \%$} & \multirow{2}{*}{$p$} \\
\hline & $\mathrm{n}$ & $\%$ & $\mathbf{N}$ & $\%$ & $\mathbf{N}$ & $\%$ & & & \\
\hline \multicolumn{10}{|l|}{$\begin{array}{l}\text { Supervised } \\
\text { treatment }\end{array}$} \\
\hline Yes & 6.181 & $65.2 \%$ & 1,895 & $54.9 \%$ & 8,076 & $62.4 \%$ & 1.00 & & \\
\hline No & 3.300 & $34.8 \%$ & 1,556 & $45.1 \%$ & 4,856 & $37.6 \%$ & 0.65 & $\begin{array}{l}0.6- \\
0.7\end{array}$ & $0.001^{\mathrm{b}}$ \\
\hline \multicolumn{10}{|l|}{$\begin{array}{l}\text { Search for } \\
\text { contacts }\end{array}$} \\
\hline Yes & 8.572 & $81.4 \%$ & 2,359 & $61.2 \%$ & 10,931 & $76.0 \%$ & 1.00 & & \\
\hline No & 1.958 & $18.6 \%$ & 1,495 & $38.8 \%$ & 3,453 & $24.0 \%$ & 0.36 & $\begin{array}{l}0.33- \\
0.39\end{array}$ & $\begin{array}{l}<.001^{\mathrm{b}} \\
\text { b }\end{array}$ \\
\hline \multicolumn{10}{|l|}{ Alcohol abuse } \\
\hline Yes & 769 & $8.7 \%$ & 524 & $17.2 \%$ & 1,293 & $10.9 \%$ & 1.00 & & \\
\hline No & 8.066 & $91.3 \%$ & 2,517 & $82.8 \%$ & 10,583 & $89.1 \%$ & 2.18 & $\begin{array}{l}1.94- \\
2.46\end{array}$ & $\begin{array}{l}< \\
0.001^{b}\end{array}$ \\
\hline \multicolumn{10}{|l|}{ FH coverage } \\
\hline $\begin{array}{l}4 \text { to } 18 \\
\text { months }\end{array}$ & 1.211 & $26.8 \%$ & 417 & $25.8 \%$ & 1,628 & $26.6 \%$ & 1.00 & & \\
\hline $\begin{array}{l}>18 \text { to } 35 \\
\text { months }\end{array}$ & 1.766 & $39.1 \%$ & 680 & $42.0 \%$ & 2,446 & $39.9 \%$ & 0.89 & $\begin{array}{l}0.78- \\
1.03\end{array}$ & 0.115 \\
\hline $\begin{array}{l}>35 \text { to } 41 \\
\text { months }\end{array}$ & 418 & $9.3 \%$ & 124 & $7.7 \%$ & 542 & $8.8 \%$ & 1.16 & $\begin{array}{l}0.92- \\
1.46\end{array}$ & 0.207 \\
\hline $\begin{array}{l}>41 \\
\text { months }\end{array}$ & 1.118 & $24.8 \%$ & 397 & $24.5 \%$ & 1,515 & $24.7 \%$ & 0.97 & $\begin{array}{l}0.83- \\
1.14\end{array}$ & 0.717 \\
\hline \multicolumn{10}{|c|}{ SOURCE: Municipal databases of SINAN-TB and IBGE, 2010. Updated 10/01/2016. } \\
\hline \multicolumn{10}{|c|}{ Abbreviations: $n$, sampling size; OR, odds ratio; SD, standard deviation; p-value, significance level. } \\
\hline a reference catego & tatist & signi & 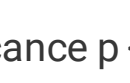 & 05 & & & & & \\
\hline
\end{tabular}

People without AIDS coinfection were 3.46 (95\% Cl: 3.07-3.91) times more likely of being cured when compared to people with coinfection. Similarly, people with negative HIV serology were 3.67 ( $95 \% \mathrm{Cl} 3.28-$ 4.12) times more likely of being cured compared to people with positive serology. On the other hand, people with unsupervised treatment were less likely to be cured (OR $0.65,95 \% \mathrm{Cl} 0.60-0.70)$ compared with those whose treatment was supervised, and people whose cases had no search for contacts were also less likely to 
be cured (OR $0.36,95 \% \mathrm{Cl} 0.33-0.39)$ compared to those who did. In relation to the Family Health coverage, a slightly higher probability of cure is perceived the higher the coverage, but without statistical significance.

The map of probability of the TB cure was performed using the spatial generalized additive model (GAM). Thus, it was assumed that "cases" were all cases of TB without cure outcome (non-cure), and "controls" those records with cure outcome (Fig. 1).

It is possible to observe that people residing within the red contours in the west and south zones (right and left ends of the map) represent areas with an OR significantly above 1. People residing in those areas tend to have more the tuberculosis cure, whereas those living in the north, surrounded by the blue contour (central contour of the map) tend to have less probability of cure.

The final model of the spatial analysis of the TB cure and the socioeconomic, demographic, and epidemiological variables using the generalized additive model is presented in Table 2. 
Table 2

The final model of the spatial analysis of the tuberculosis cure and the socioeconomic, demographic, and epidemiological variables.

\begin{tabular}{|c|c|c|c|c|c|}
\hline Variable & Coefficient & Error & OR & Cl $95 \%$ & $p$-value \\
\hline Coverage 4 to 18 months & 0.3101913 & 0.1337 & 1.36 & $1.04-1.77$ & $0.020 *$ \\
\hline Coverage $>35$ months to 41 months & 0.4972078 & 0.2178 & 1.64 & $1.07-2.51$ & $0.022 *$ \\
\hline Coverage $>41$ months & 0.0982589 & 0.1378 & 1.10 & $0.84-1.44$ & 0.476 \\
\hline Alcohol abuse (yes) & -0.7423219 & 0.1556 & 0.47 & $0.35-0.64$ & $<0,001 *$ \\
\hline Primary School & 0.1327906 & 0.1345 & 1.14 & $0.87-1.48$ & 0.323 \\
\hline Secondary School & 0.5474371 & 0.1454 & 1.72 & $1.30-2.29$ & $<0,001 *$ \\
\hline Higher Education & 0.4809512 & 0.2641 & 1.61 & $0.96-2.71$ & 0.068 \\
\hline Search for contacts (yes) & 0.6972460 & 0.1273 & 2.00 & $1.56-2.57$ & $<0,001 *$ \\
\hline Positive serology for HIV (yes) & -1.1426839 & 0.1470 & 0.31 & $0.23-0.42$ & $<0,001 *$ \\
\hline Supervised treatment (yes) & 0.1781498 & 0.1271 & 1.19 & $0.93-1.53$ & 0.160 \\
\hline Age 0 to 25 years & 0.0005724 & 0.1332 & 1.00 & $0.77-1.29$ & 0.996 \\
\hline Age $>50$ to 80 years & 0.3062125 & 0.1339 & 1.35 & $1.04-1.76$ & $0.022^{*}$ \\
\hline Age $>80$ years & -1.1596947 & 0.5508 & 0.31 & $0.10-0.92$ & $0.035^{\star}$ \\
\hline Aging rate & 2.2402193 & 1.1253 & 9.39 & $1.03-85.26$ & $0.046 *$ \\
\hline \multicolumn{6}{|c|}{ SOURCE: Municipal databases of SINAN-TB and IBGE, 2010. Updated 10/01/2016. } \\
\hline \multicolumn{6}{|l|}{ Deviance: 9.16\%; AIC/UBRE: -0.049082 } \\
\hline \multicolumn{6}{|c|}{ Abbreviations: OR odds ratio; $\mathrm{Cl}$ 95\%, 95\% confidence interval; $\mathrm{p}$-value, significance level. } \\
\hline
\end{tabular}

The family health coverage variable, measured here as time lapse of PHC and the time of diagnosis, was significant for the categories "4 to 18 months" and "> 35 months to 41 months" OR 1.36 (95\% Cl 1.04-1.77) and OR 1.64 (95\% Cl 1.07-2.51) respectively. People with a history of alcohol abuse had almost half the probability of cure (OR $0.47,95 \% \mathrm{CI} 0.35-0.64)$ when compared to people with no history of alcohol abuse. There was a positive trend in the association between the educational level and the probability of TB cure, especially in the case of secondary school students, with 1.72 times the probability of cure $(95 \% \mathrm{Cl} 1.30-$ 2.29) compared to illiterate people. People who had positive HIV serology were 0.31 (95\% $\mathrm{Cl} 0.23-0.42)$ times less likely of achieving cure. On the other hand, people residing in census tracts with higher aging rates were 9.39 (95\% Cl 1.03-85.26) times more likely of achieving cure.

The map of the final spatial model can be visualized in Fig. 2. It is the smoothed spatial component, adjusted for the other socioeconomic, demographic, and epidemiological variables of the final model. Significant 
spatial association was found $(p=0.0219)$. The areas surrounded by green dotted lines had positive spatial correlation for cure, whereas red dotted lines had inverse spatial correlation with cure.

\section{Discussion}

In Brazil, there are few studies on the spatial distribution of endemic diseases, such as TB, in urban areas. The information about the spatial and temporal spread of these diseases allows to understand the occurrence of these events in the territory. In addition, the description and visualization of the spatial distribution of the event facilitate the identification of its association with local characteristics, such as socioeconomic conditions.

The cure rate of $71.57 \%$ was lower than the value found in other studies conducted in other regions of the country, such as Silva et al (2014) $)^{11}$, who found $90.9 \%$ of the cases closed due to cure in Maranhão. However, it is better than in Crato (CE), where Pinto et al $(2015)^{12}$ found a cure rate of $47.2 \%$.

Spatial analysis demonstrated a significant spatial association with TB cure. In addition, the TB cure probability map shows that the southern and western zones were more likely to be cured from tuberculosis while residents living in the north were less likely to be cured. This result can be useful as a public health policy since it is possible to prioritize this region to improve TB cure in MRJ. Possibly, the regions with the greatest probability of cure were associated with greater coverage of the family health strategy, such as in the western part of the municipality, covering more than $90 \%$ since 2010 , in addition to Rocinha with $100 \%$ coverage since 2012. On the other hand, for the rest of the southern zone and the Tijuca region, it is probably due to much easier access to other health facilities, better socioeconomic situation, and retention of physicians with good qualification.

From the spatial analysis, it was possible to perceive, as expected, an association between the tuberculosis cure and better socioeconomic conditions such as educational level and income. Despite the association between race / color and cure in bivariate analysis, no association was found in the final spatial analysis model. Possibly, this variable has bad data entry problems. The spatial model demonstrated that the higher the educational level, the better the probability of cure, which is consistent with that expected from the literature ${ }^{11,13}$.

There was an apparent paradox between the lower probability of cure among the elderly, when analyzing the variable age at the individual level and the higher probability of cure the higher the aging rate at the level of the census tract. This may be since, at the individual level, older patients have lower adherence to treatment due to intrinsic factors, leading to more adverse effects, increased drug interaction, forgetfulness of taking medication and less immunity. On the other hand, those patients residing in census tracts with higher rates of aging have a greater likelihood of cure, probably because this variable represents more structured communities from the socioeconomic viewpoint, which could have a longer life expectancy, and from a temporal viewpoint, because they were possibly older migration communities and with a larger social support network that would favor a better treatment and consequently a better probability of cure. It is worth noting that the aging rate was the variable that showed the highest probability of cure (OR 9.39), with the greatest variability (95\% $\mathrm{Cl} 1.03-85.26)$, evidencing the importance of the social context for TB cure. The positive 
serology for HIV and alcohol abuse variables were associated with a lower probability of TB cure. In addition to the expected lower immunity, these patients may show less adherence, due to drug interaction and greater occurrence of medication side effects ${ }^{29,30}$.

It can be observed that the longer the implantation time of family health teams since the diagnosis of the disease, the greater the probability of TB cure, except for the category of 41 months or more, which evidenced the worst probability of cure among the categories. Data of this study were insufficient to explain this phenomenon since it would be expected that teams with 41 months or more would be more likely to cure. One possible explanation is that the first family health teams in the MRJ were deployed in very vulnerable regions and, despite MRJ efforts, some of them remained for a long time without being complete due to lack of doctors. This type of study does not allow a correlation between cause and effect and the external validity may not be reached. Other studies are necessary to confirm or not the results founded.

\section{Conclusion}

The spatial analysis of cases of the tuberculosis cure in the years 2012 to 2014 showed a significant spatial association with the tuberculosis cure. In addition, regions in the municipality with more probability of the cure were evidenced, which favors the manager to implement more efficient TB control measures. Regarding $\mathrm{PHC}$ coverage, a significant association was found between TB cure and time of family health implantation when the socioeconomic variables were controlled. This finding corroborates the importance of treating tuberculosis in this level of care.

\section{Abbreviations}

TB: Tuberculosis; WHO: World Health Organization; SINAN-TB: Notifiable Diseases Information System for Tuberculosis; GAM: generalized additive model; HIV: human immunodeficiency virus; Cl: confidence interval; PCH: primary health care; MRJ: municipality of Rio de Janeiro; API: Application Programming Interface; IBGE: Brazilian Institute of Geography and Statistics; RS: Real (official currency of Brazil); AIDS: acquired immunodeficiency syndrome; OR: odds ratio.

\section{Declarations}

\section{Ethical approval}

This study was approved by the Ethics Committee of Municipal Health Secretariat in Rio de Janeiro, under opinion $N^{\circ}$ 1.389.137 and CAAE protocol 52493216.5.0000.5279, in compliance with the recommendations contained in Resolution 466/12 of the National Health Council. The rules of the Helsinki Convention were followed.

\section{Consent to publish}

Not applicable

\section{Availability of data and materials}


The datasets analyzed in this study consisted of all confirmed cases of tuberculosis, considering the International Classification of Diseases 10th revision (ICD-10). Data recorded in the Notification of Injury Information System (SINAN), that supporting the results of this study are available from Municipal Health Department of Rio de Janeiro. The data are, however, available by the authors upon reasonable request and with permission of Municipal Health Department of Rio de Janeiro. For the construction of the spatial analysis maps, we used the cartographic base of the municipality of Rio de Janeiro, available in the electronic database of the Brazilian Institute of Geography and Statistics (IBGE).

\section{Competing interests}

The authors declare no competing interests.

\section{Funding}

This work has not receipted any research funding. The authors used only the facilities of the Department of Infectious and Parasitic Diseases of the Faculty of Medicine of the Federal University of Rio de Janeiro: computers, paper, and printer toner.

\section{Authors' contributions}

JCPJ and RAM involved in the conception, design, acquisition of data, analysis, and interpretation of the results, then drafted the manuscript and sent for publication. The authors read and approved the final manuscript.

\section{Acknowledgements}

Not applicable.

\section{References}

1. Geneva. World Health Organization. Global tuberculosis report 2015. 20th ed. 2015.

2. Brasil. Ministério da Saúde. Secretaria de Vigilância em Saúde. Boletim Epidemiológico 2016: Perspectivas brasileiras para o fim da tuberculose como problema de saúde pública. Vol 47, 2016.

3. Souza MSPL, Aquino R, Pereira SM, et al. Fatores associados ao acesso geográfico aos serviços de saúde por pessoas com tuberculose em três capitais do Nordeste brasileiro. Cad Saude Publica. 2015;31(1):111-20.

4. Starfield B. Primary Care: balancing health needs, services, and technology. Brasília. UNESCO, Ministério da Saúde, 2002.

5. Maquieviz J, Alves IS, Neves EB, Ulbricht L. A Estratégia de Saúde da Família no controle da tuberculose em Curitiba (PR). Cien Saude Colet. 2013;18(1):265-71.

6. Campos CEA, Cohn A, Brandao AL. The historical trajectory of the city of Rio de Janeiro's health system: 1916-2015. One hundred years of innovations and achievements. Cien Saude Colet. 2016;21(5):135164. 
7. Soranz D, Pinto LF, Penna GO. Themes and Reform of Primary Health Care (RCAPS) in the city of Rio de Janeiro, Brazil. Cien Saude Colet. 2016;21(5):1327-38.

8. Santos-Neto M. Análise espacial dos óbitos por tuberculose pulmonar e sua relação com indicadores sociais em São Luís - MA. 2014. 105 p. Tese (Doutorado) - Escola de Enfermagem de Ribeirão Preto, Universidade de São Paulo, Ribeirão Preto, 2014.

9. San-Pedro A, Oliveira RM. Tuberculose e indicadores socioeconômicos: revisão sistemática da literatura. Rev Panam Salud Publ. 2013;33(4):294-301.

10. Magalhaes MAFM, Matos VP, Medronho RA. Avaliação do dado sobre endereço no Sistema de Informação de Agravos de Notificação utilizando georreferenciamento em nível local de casos de tuberculose por dois métodos no município do Rio de Janeiro. Cad Saude Colet. 2014;22(2):192-9.

11. Silva PF, Moura GS, Caldas AJM. Fatores associados ao abandono do tratamento da tuberculose pulmonar no Maranhão, Brasil, no período de 2001 a 2010. Cad Saude Publica. 2014;30(8):1745-54.

12. Pinto ML, Silva TC, Gomes LCF, et al. Occurrence of tuberculosis cases in Crato, Ceará, from 2002 to 2011: a spatial analysis of specific standards. Rev Bras Epidemiol. 2015;18(2):313-25.

13. Silva CCAV, Andrade MS, Cardoso MD. Fatores associados ao abandono do tratamento de tuberculose em indivíduos acompanhados em unidades de saúde de referência na cidade do Recife, Estado de Pernambuco, Brasil, entre 2005 e 2010. Epidemiol Serv Saude. 2013;22(1):77-85.

14. IBGE. Instituto Brasileiro de Geografia e Estatística. Estimativas da população. Rio de Janeiro: IGBE, 2016. Available from:

<http://www.ibge.gov.br/home/estatistica/populacao/estimativa2015/serie_2001_2015_tcu.shtm>.

15. IBGE. Instituto Brasileiro de Geografia e Estatística. Censo Demográfico 2010. Rio de Janeiro: Resultados do Universo por setor censitário. Rio de Janeiro: IBGE, 2011, p201. Available from: <ftp://ftp.ibge.gov.br/Censos/Censo_Demografico_2010/Sinopse/Agregados_por_Setores_Censitarios/>.

16. R Development Core Team (2016). R: A language and environment for statistical computing. $R$ Foundation for Statistical Computing, Vienna, Austria. ISBN 3-900051-07-0, <Available from: http://www.R-project.org>

17. Wood SN. Generalized Additive Models: An Introduction with R. Chapman and Hall/CRC, 2006.

18. ESRI. ArcGIS, Desktop. Release 10. Redlands: Environmental Systems Research Institute. 2011.

19. Fox J, Weisberg S. car: Companion to Applied Regression. R package version 2.1-2, 2016. Available from http://CRAN.R-project.org/package=car.

20. Wood SN. mgcv: Mixed GAM Computation Vehicle with GCV/AIC/REML Smoothness Estimation. version 1.8-12, 2016. Available from http://CRAN.R-project.org/package=mgcv.

21. Aquino J. Descriptive Statistics. R package version 1.1.3, 2016. Available from http://CRAN.Rproject.org/package $=$ descr.

22. Pebesma E, Bivand R. sp: Classes and Methods for Spatial Data. R package version 1.2-3, 2016. Available from http://CRAN.R-project.org/package=sp.

23. Bivand R. spdep: Spatial dependence: weighting schemes, statistics and models. R package version 0.65, 2016. Available from http://CRAN.R-project.org/package=spdep. 
24. Bivand R, Lewin-Koh N. maptools. Tools for reading and handling spatial objects. R package version 0.8-39, 2016. Available from http://CRAN.R-project.org/package=maptools.

25. Rowlingson B, Diggle P. splancs: Spatial and Space-Time Point Pattern Analysis. R package version 2.0138, 2015. Available from http://CRAN.R-project.org/package=splancs.

26. Nychka D, Furrer R, Paige J, Sain S. fields: Tools for spatial data. R package version 8.4.1, 2016. Available from http://CRAN.R-project.org/package=fields.

27. Neuwirth E, RColorBrewer. ColorBrewer palettes. R package version 1.1-2, 2015. http://CRAN.Rproject.org/package $=$ RColorBrewer.

28. Wickham H, Chang W. ggplot2: An Implementation of the Grammar of Graphics. version 2.1.0, 2016. Available from http://CRAN.R-project.org/package=ggplot2.

29. Ambadekar NN, Zodpey SP, Soni RN, Lanjewar SP. Treatment outcome and its attributes in TB-HIV coinfected patients registered under Revised National TB Control Program: a retrospective cohort analysis. Public Health. 2015;129(6):783-9.

30. Gebremariam G, Asmamaw G, Hussen M, et al. Impact of HIV Status on Treatment Outcome of Tuberculosis Patients Registered at Arsi Negele Health Center, Southern Ethiopia: A Six Year Retrospective Study. PLoS One. 2016;11(4):e0153239.

\section{Figures}

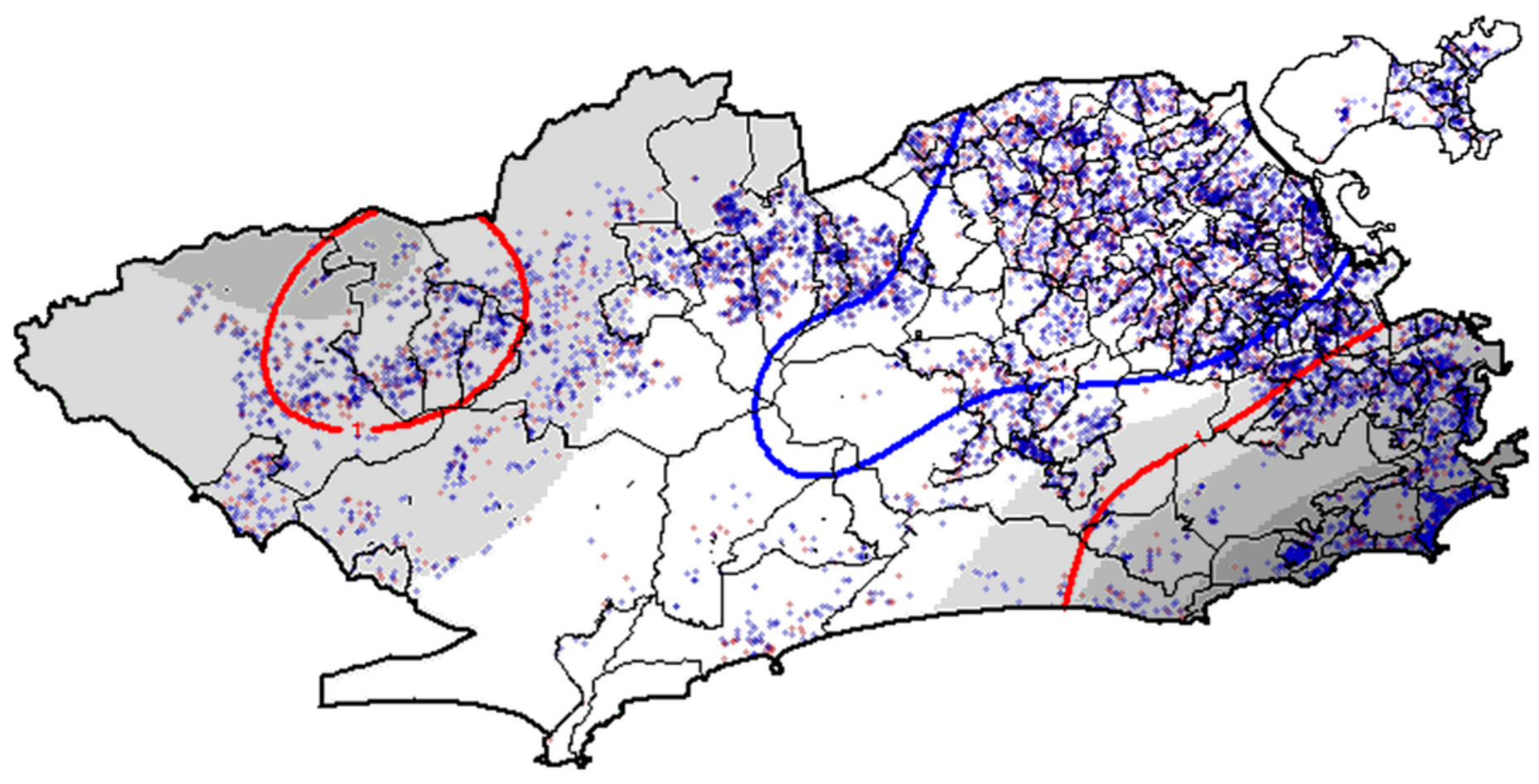

\section{Figure 1}

The map of probability of the TB cure was performed using the spatial generalized additive model (GAM). Thus, it was assumed that "cases" were all cases of TB without cure outcome (non-cure), and "controls" 
those records with cure outcome Note: The designations employed and the presentation of the material on this map do not imply the expression of any opinion whatsoever on the part of Research Square concerning the legal status of any country, territory, city or area or of its authorities, or concerning the delimitation of its frontiers or boundaries. This map has been provided by the authors.

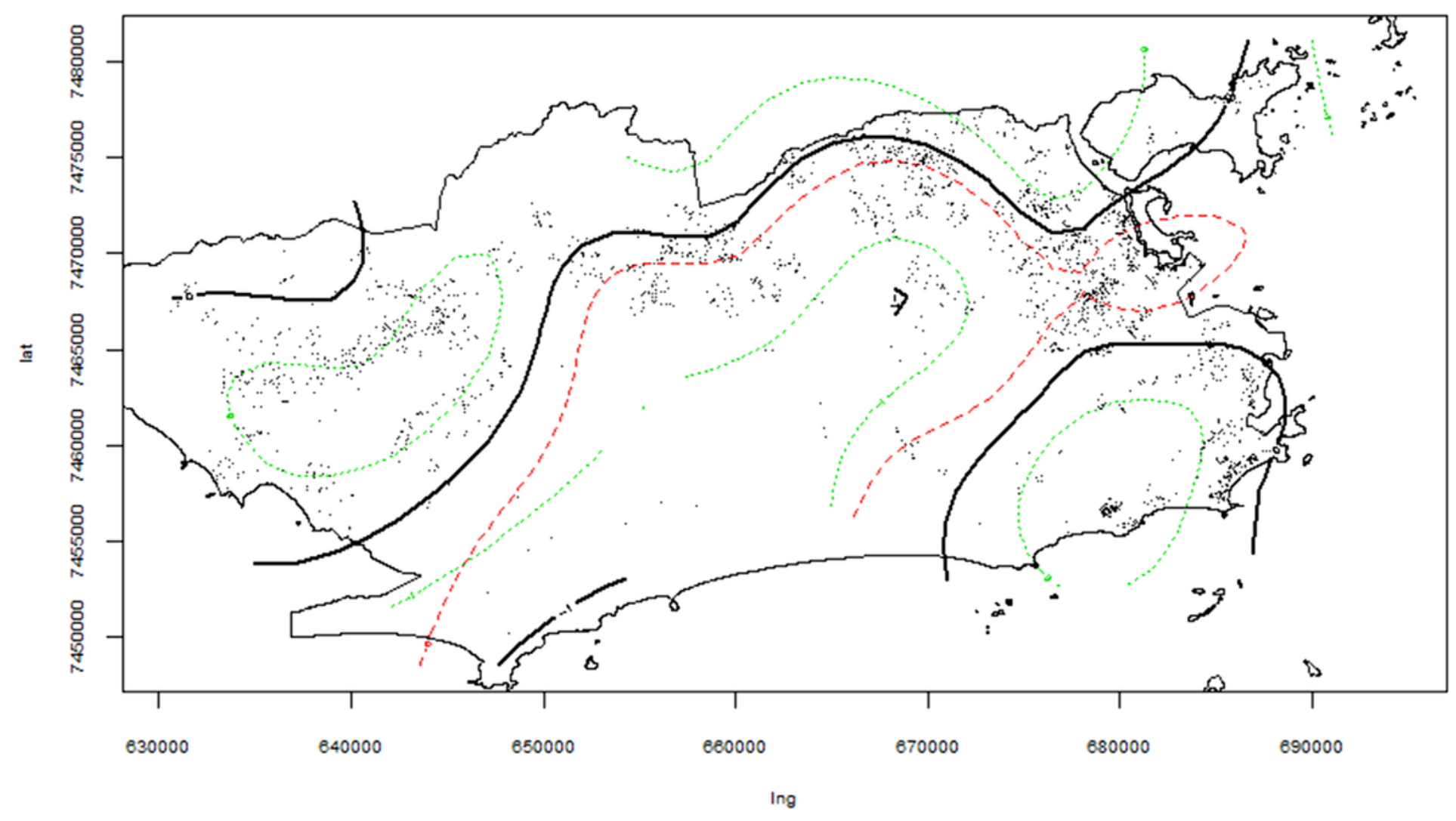

Figure 2

It is the smoothed spatial component, adjusted for the other socioeconomic, demographic, and epidemiological variables of the final model. Significant spatial association was found $(p=0.0219)$. The areas surrounded by green dotted lines had positive spatial correlation for cure, whereas red dotted lines had inverse spatial correlation with cure. Note: The designations employed and the presentation of the material on this map do not imply the expression of any opinion whatsoever on the part of Research Square concerning the legal status of any country, territory, city or area or of its authorities, or concerning the delimitation of its frontiers or boundaries. This map has been provided by the authors.

\section{Supplementary Files}

This is a list of supplementary files associated with this preprint. Click to download.

- STROBEchecklistSpatialanalysisTB.doc 